\title{
Time for New Reference Values for Ventilatory Lung Function
}

\author{
W. Marek ${ }^{1}$, E. Marek ${ }^{1}$, K. Mückenhoff ${ }^{2}$, H-J. Smith ${ }^{3}$, P. Degens ${ }^{4}$, N. Kotschy-Lang ${ }^{5}$, M. Kohlhäufl ${ }^{6}$ \\ ${ }^{1}$ Institute of Occupational Physiology, Augusta-Kranken-Anstalt, Bochum; ${ }^{2}$ Institute of Physiology, Ruhr-Universität Bochum; ${ }^{3}$ Cardinal \\ Health, Höchberg; ${ }^{4}$ Forschungsinstitut für Arbeitsmedizin der Deutschen Gesetzlichen Unfallversicherung, Bochum; \\ ${ }^{5}$ Berufsgenossenschaftliche Klinik für Berufskrankheiten Falkenstein; ${ }^{6}$ Klinik Schillerhöhe, Center for Pulmonolgy and Thoracic Surgery, \\ Academic Teaching Hospital, University of Tübingen, Stuttgart-Gerlingen, Germany
}

\begin{abstract}
Objective: The anthropometrical data of our aging population has significantly changed within the last five decades. Therefore the question arises whether or not the commonly used reference values of the European Community (ECCS) for lung function, may still be accepted today. Measured values for elderly are classified by extrapolation beyond the range of reference equations.

Material and methods: Lung function was examined by pneumotachography for recording static lung volumes and flow-volume-curves in 257 asymptomatic non smoking males, aged 20-90 years. Results were compared to the reference values of ECCS, SAPALDIA, LuftiBus, and NHANES.

Results: For analysis age and height dependence of investigated respiratory parameters (VC, FVC, FEV ${ }_{1}$, $\left.\mathrm{FEV}_{1} \% \mathrm{FVC}, \mathrm{PEF}, \mathrm{MEF}_{75,50,25}\right)$ can for simplicity be described by linear functions $(y=a \cdot h e i g h t(H)-b \cdot a g e$ $(\mathrm{A})+\mathrm{c})$. The forced expiratory volume in one second, $\mathrm{FEV}_{1}$, was calculated by $\mathrm{FEV}_{1}=0.0432 \cdot \mathrm{H}-0.0347 \cdot \mathrm{A}$ -2.114; where $\mathrm{H}$ - height, $\mathrm{A}$ - age; $\mathrm{r}=0.78$. Mean $\mathrm{FEV}_{1}$ for younger subjects was found to be $106.1 \pm$ $11.2 \%$ of the ECCS reference values and $97.8 \pm$ $11.7 \%$ in older subjects. For all parameters investigated linear regressions on age were steeper than described by the ECCS reference values. The regression of lung function to height largely follows the ECCS prescriptions.

Summary: Bochum lung function values of healthy subjects showed a steeper age descent compared to the reference values of the ECCS. The alternatively discussed reference values of the SAPALDIA-, NHANES- or LuftiBus-Study are higher, but do not cover all necessary parameters and/or the age range. A multi centre study for contemporary reference values is recommended.
\end{abstract}

Key words: lung function, reference values, elderly males, spirometry, forced expiration

\section{INTRODUCTION}

The structure of our aging population has significantly changed along with anthropometrical data in the last five decades. Therefore the question arises whether or not the commonly used reference values of ventilatory lung function, which were suggested by the European
Community for Coal and Steel (ECCS) [1, 2], may still be accepted today, since these values were obtained in the sixties and seventies from subjects with a restricted range of age and body height. Birth cohort effects and improved technology should be considered. Measured values are classified for elderly by extrapolated reference equations which have been obtained from a different population beyond the range. Therefore decisions in elder and smaller subjects concerning compensation due to impaired lung function after industrial exposure on the basis of ECCS-values are questionable. In the last decades several new reference equations were published, finding higher values for lung function [3-8], which replaced the former recommendations [9-13]. Compared to the recently published recommendations, ECCS-values are lower, and the lower limit values or the $5^{\text {th }}$ percentile may not represent the cut off point between "normal" and "diseased".

Three models may be discussed for the changes in lung function related to aging. After the age of 65 a normal course of aging could result in a further linear decrease in spirometric parameters with the same slope as observed in middle aged groups [14]. Secondly, healthy older subjects may have nearly constant values for lung function. Finally, accumulation of diseases may result in a steeper decrease in lung function, as observed in patients with COPD or in heavy smokers [15-17].

The current reference formulas available from the literature are incomplete concerning spirometric parameters (Hankinson [3], only $\mathrm{FVC}, \mathrm{FEV}_{1}, \mathrm{FEV}_{6}$, PEF, $\mathrm{FEF}_{25-75}$ ) the range of age (Brändli et al. [4] 2060 years, $\mathrm{FEV}_{1}, \mathrm{FVC}, \mathrm{FEV}_{1} \% \mathrm{FVC}, \mathrm{PEF}, \mathrm{MEF}_{75,50,25}$, $\mathrm{MEF}_{25-75}$ ), or contain, as e.g., the Luftibus-Study, a selection bias, since only subjects were investigated who paid for a lung function test because of their personal request (Kuster et al. [6] $\mathrm{FEV}_{1}, \mathrm{FVC}, \mathrm{FEV}_{1} \% \mathrm{FVC}$, PEF, $\left.\mathrm{MEF}_{75,50,25}\right)$. In order to perform a comprehensive diagnosis of lung function, static and dynamic lung volumes from spirometry and residual volume (RV) from Helium dilution or even from body plethysmography are needed along with PEF and $\mathrm{MEF}_{75,50,25}$ - values from flow-volume-curves. A complete set of parameters is available only from ECCS recommendations $[1,2]$.

A linear extrapolation of the ECCS reference equations would be the most simple temporary solution; 
however, an extrapolation is not generally recommended. But all manufactures have implemented the extrapolation in their systems and lung function laboratories largely use them. This procedure however does not base on a scientific background and raises the question, if one can rely on diagnosis of lung function based on extrapolations.

The European Task Force on standardisation of lung function testing has recently published a series of comprehensive recommendations for lung function testing and interpretation [18-20]. The problems of the lower limit values and the restricted age range however were not solved.

We checked on a small, but carefully chosen group of healthy never smoking males aged 18 to 90 years and 160 to $203 \mathrm{~cm}$ body height, if the ECCS reference recommendation still can be accepted in daily routine measurements, if an extrapolation of the ECCS reference values can be performed, or if the deterioration of lung function is different from a linear decline in higher ages. From the results, a 'Bochum' set of reference formulas for lung function parameters in healthy non-smoking males were calculated by multiple linear regression analysis for discussion.

\section{Material AND Methods}

Lung function was examined using pneumotachography for recording static lung volumes and flow-volume-curves in 257 asymptomatic non smoking Caucasian males, aged 20-90 years. Subjects were without diseases of the lung, heart or other organs. The subjects were recruited among healthy non-smoking staff members from the hospital, volunteers, and subjects introducing themselves for a health check to enter a life insurance. Competitive athletes or employers performing severe physical work were not recruited. The anthropometrical data are presented in Table 1.

\section{ANTHRopometrical Data}

The body height of the males, recruited in the cross sectional study correlated significantly to age, height $=$ $-0.173 \cdot$ age $+185 \mathrm{~cm}(\mathrm{r}=0.49, \mathrm{P}<0.01)$. The mean height of a 25 years old young subject was $181 \mathrm{~cm}$ and $173 \mathrm{~cm}$ for an 80 years old male. BMI significantly increased with age, BMI $=0.056 \cdot$ age $+22.5(\mathrm{r}=0.37$, $\mathrm{P}<0.01)$. For the younger group, BMI was $23.6 \pm 3.0$ and $25.8 \pm 2.4(\mathrm{P}<0.005)$ for the elderly group. BMI showed a tendency to decrease with height BMI = -0.0723 height $+37.9,(\mathrm{r}=0.37, \mathrm{P}<0.05)$. There was a slight tendency to lower BMI indices with increasing height, $\mathrm{BMI}=-0.084 \cdot$ height $+40.2(\mathrm{r}=0.20, \mathrm{P}<0.05)$.

\section{Lung Function Measurements}

Lung function measurements [21] of static and dynamic lung volumes and maximal expiratory flows, using MasterLab, or PneumoScreen systems (Cardinal Health, Höchberg) were performed according to the recommendations and reference formulas of the ECCS [2]. According to the manufactures guidelines, calibrations were performed daily. After recording static lung volumes, three flow volume manoeuvres were performed, starting from residual volume (RV) with a forced inspiration. Only measurements were accepted with times for expiration (TE) exceeding four seconds and without cough disturbed expirations.

\section{DATA ANALYSIS}

From the results multiple linear regression lines were calculated for age (20-90 years) and body height (160$203 \mathrm{~cm})$. The reference formulas for spirometric parameters recorded in the present Bochum study were compared to the reference values of the ECCS, SAPALDIA, LuftiBus and Hankinson studies. The results are presented as means $\pm \mathrm{SD}$, along with the median. Using Fisher's paired t-test, differences of mean values were proofed to be significantly different from reference values of ECCS, SAPALDIA- or LuftiBus- values [22]. $\mathrm{P}<0.05$ was accepted as significantly different.

\section{RESULTS \\ Correlation of Lung Function Parameters TO AgE}

For healthy subjects, the relationship to age of all respiratory parameters investigated $\left(\mathrm{VC}, \mathrm{FVC}, \mathrm{FEV}_{1}\right.$, $\left.\mathrm{FEV}_{1} \% \mathrm{FVC}, \mathrm{PEF}, \mathrm{MEF}_{75,50,25}\right)$ can be described with linear regressions $(y=-m \cdot a g e+n)$ for comparison with the ECCS reference equations with extended age range until 90 years of age $(\mathrm{P}<0.01)$. Forced expiratory volume in one second, $\mathrm{FEV}_{1}$, is represented by $\mathrm{FEV}_{1}=-0.043 \cdot$ age $+5.93 ; \mathrm{r}^{2}=0.74$ (Fig. 1). The mean $\mathrm{FEV}_{1}$ for younger subjects was $106 \pm 11.0 \%$ of the EGKS reference values, $104 \pm 14.1 \%$ in middle

Table 1. Anthropometrical data of the elderly, middle aged, and younger subjects included in the study.

\begin{tabular}{lllll|llll|llll}
\hline \multicolumn{3}{c|}{ Elderly males $(\mathrm{n}=53)$} & \multicolumn{3}{c|}{ Middle aged males $(\mathrm{n}=50)$} & \multicolumn{3}{c}{ Younger males $(\mathrm{n}=154)$} \\
\hline & $\begin{array}{l}\text { Age } \\
(\text { years })\end{array}$ & $\begin{array}{l}\text { Height } \\
(\mathrm{cm})\end{array}$ & $\begin{array}{l}\text { Weight } \\
(\mathrm{kg})\end{array}$ & BMI & $\begin{array}{l}\text { Age } \\
\text { (years) }\end{array}$ & $\begin{array}{l}\text { Height } \\
(\mathrm{cm})\end{array}$ & $\begin{array}{l}\text { Weight } \\
(\mathrm{kg})\end{array}$ & BMI & $\begin{array}{l}\text { Age } \\
(\text { years })\end{array}$ & $\begin{array}{l}\text { Height } \\
(\mathrm{cm})\end{array}$ & $\begin{array}{l}\text { Weight } \\
(\mathrm{kg})\end{array}$ & BMI \\
\hline MW & 74.0 & 173 & 77.4 & 25.8 & 57.1 & 177 & 83.8 & 26,8 & 25.4 & 181 & 77.7 & 23.6 \\
STD & \pm 6.4 & \pm 7.4 & \pm 10.3 & \pm 2.4 & \pm 6.4 & \pm 6.5 & \pm 9.4 & \pm 2.7 & \pm 4.9 & \pm 6.5 & \pm 11.1 & \pm 3.0 \\
MAX & 90 & 187 & 100 & 31.6 & 65 & 197 & 106 & 32.1 & 40 & 203 & 123 & 35.3 \\
MIN & 66 & 159 & 60 & 21.7 & 41 & 166 & 68 & 20.5 & 20 & 164 & 55 & 17.0 \\
MED & 72 & 173 & 75 & 25,8 & 60 & 175 & 83 & 26.9 & 25 & 180 & 75 & 23.3 \\
\hline
\end{tabular}



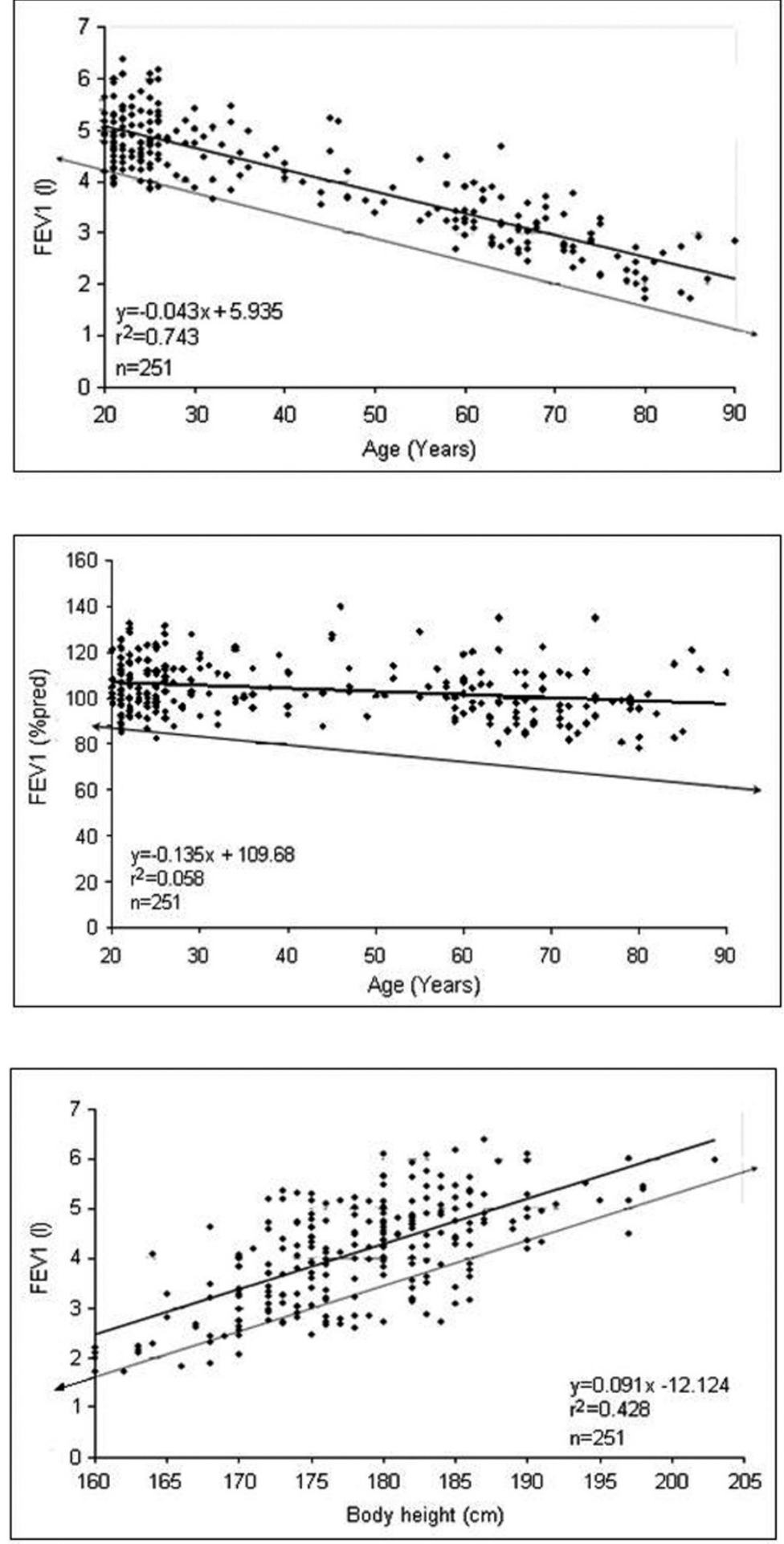

Fig. 1. Regression of $\mathrm{FEV}_{1}$ on age for healthy non-smoking male adults between 20 and 90 years.
Fig. 2. Regression of $\mathrm{FEV}_{1}$ (in \%predicted of ECCS) on age for healthy non-smoking male adults.
Fig. 3. Regression of $\mathrm{FEV}_{1}$ on body height for healthy non-smoking male adults with body heights ranging from 160 to $203 \mathrm{~cm}$. aged group and $98 \pm 12.5 \%$ in the older subjects. Lung function parameters calculated as \%predicted also significantly correlate to age $(\mathrm{P}<0.01)$. $\mathrm{FEV}_{1} \%$ pred is represented by $\mathrm{FEV}_{1}$ pred $=-0.135 \cdot$ age $+109.68 ; \mathrm{r}^{2}$ $=0.06$ (Fig. 2).

\section{Correlation of Lung Function Parameters to BODY HEIGHT}

Lung function parameters, in absolute values and in \%predicted are in accordance with ECCS reference values of body height, indicating a representative match with ECCS reference values. The correspondence of $\mathrm{FEV}_{1}$ and body height can be described as $\mathrm{FEV}_{1}=0.091 \cdot$ height $-12.12 ; \mathrm{r}^{2}=0.43, \mathrm{P}<0.01, \mathrm{cov}-$ ering the height range 160-202 cm (Fig. 3). Lung function parameters given in \%predicted did not show a correlation to body height. These dependencies of lung function values are correctly incorporated in the formulas. $\mathrm{FEV}_{1} \%$ pred is represented by $\mathrm{FEV}_{1}$ pred $=0.14 \cdot$ height $+79.34 ; \mathrm{r}^{2}=0.009$ (Fig. 4). 


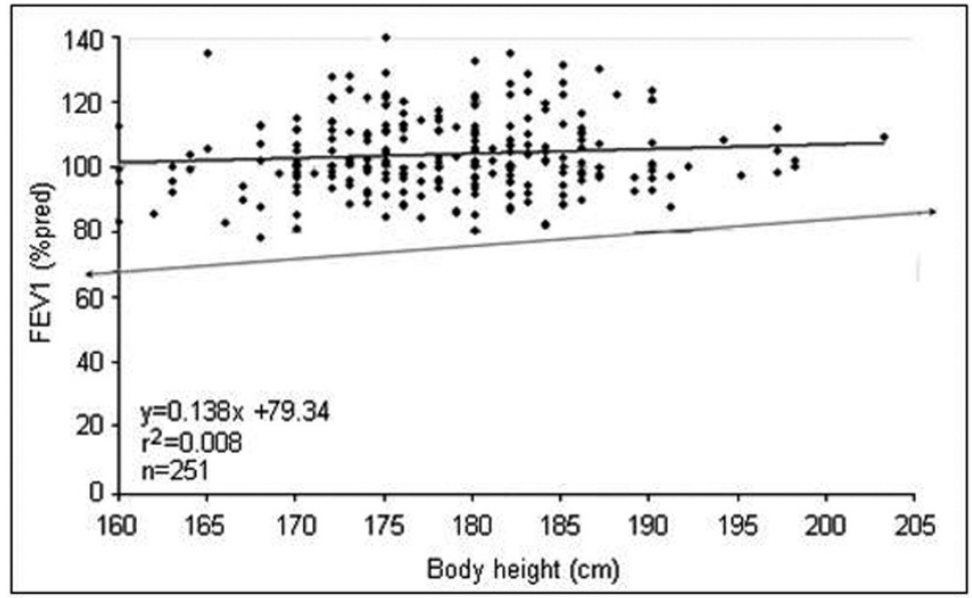

Fig. 4. Regression of $\mathrm{FEV}_{1}$ (in \%predicted of ECCS) on body height for healthy non-smoking male adults.

Table 2. Lung function parameters (in \%pred of ECCS) in elderly, middle aged and younger males.

\begin{tabular}{lcll}
\hline Parameter & $\begin{array}{l}\text { Elderly males } \\
(\mathrm{n}=53)\end{array}$ & $\begin{array}{l}\text { Middle-aged males } \\
(\mathrm{n}=50)\end{array}$ & $\begin{array}{l}\text { Younger males } \\
(\mathrm{n}=148)\end{array}$ \\
\hline VCIN (\%pred) & $94.6 \pm 11.0^{* * *}$ & $102.3 \pm 12.5$ & $100.1 \pm 10.2$ \\
FVC (\%pred) & $96.5 \pm 11.8^{*}$ & $105.3 \pm 12.7^{* *}$ & $104.7 \pm 10.7^{* *}$ \\
$\mathrm{FEV}_{1}$ (\%pred) & $97.8 \pm 11.7$ & $104.8 \pm 12.3^{* *}$ & $106.1 \pm 11.2^{* * *}$ \\
$\mathrm{FEV}_{1} \% \mathrm{VCIN}$ & $102.5 \pm 8.5^{*}$ & $101.2 \pm 7.0$ & $100.8 \pm 6.48$ \\
$\mathrm{PEF}$ (\%pred) & $96.9 \pm 14.2$ & $106.1 \pm 20.4$ & $106.2 \pm 16.4^{* * *}$ \\
$\mathrm{MEF}_{50}$ (\%pred) & $94.8 \pm 24.8$ & $94.8 \pm 27.4$ & $104.4 \pm 23.3$ \\
\hline
\end{tabular}

$* \mathrm{P}<0.05,{ }^{*} * \mathrm{P}<0.01, * * * \mathrm{P}<0.001$

Table 3. Bochum reference formulas for ventilatory lung function in healthy non-smoking males aged 20 to 90 years ( $\mathrm{n}=251)$.

\begin{tabular}{|c|c|c|c|c|}
\hline Parameter & Reference formula & $\mathrm{r}^{2}$ & RSD & $1.64 \cdot \mathrm{RSD}$ \\
\hline $\mathrm{VC}$ & $\mathrm{Y}=0.0631 . \mathrm{H}-0.0312 . \mathrm{A}-4.960$ & 0.73 & 0.58 & 0.96 \\
\hline FVC & $\mathrm{Y}=0.0615 . \mathrm{H}-0.0308 . \mathrm{A}-4.673$ & 0.74 & 0.58 & 0.96 \\
\hline $\mathrm{FEV}_{1}$ & $\mathrm{Y}=0.0431 . \mathrm{H}-0.0346 . \mathrm{A}-2.114$ & 0.78 & 0.49 & 0.81 \\
\hline $\mathrm{FEV}_{1} \% \mathrm{FVC}$ & $Y=-0.1141 . H-0.2001 . A+110$ & 0.32 & 5.72 & 9.38 \\
\hline PEF & $\mathrm{Y}=0.0742 . \mathrm{H}-0.0538 . \mathrm{A}+1.3032$ & 0.47 & 1.60 & 2.63 \\
\hline MEF75 & $\mathrm{Y}=0.0579 . \mathrm{H}-0.0227 . \mathrm{A}-1.3032$ & 0.08 & 1.73 & 2.85 \\
\hline $\mathrm{MEF}_{50}$ & $\mathrm{Y}=0.0211 . \mathrm{H}-0.0449 . \mathrm{A}+3.270$ & 0.41 & 1.26 & 2.07 \\
\hline $\mathrm{MEF}_{25}$ & $\mathrm{Y}=0.0205 . \mathrm{H}-0.0400 . \mathrm{A}-0.800$ & 0.31 & 0.68 & 1.12 \\
\hline
\end{tabular}

$\mathrm{H}$ - body height (cm); A - age (years)

\section{Lung Function Parameters Compared to Eccs REFERENCE VALUES}

The frequently used predicted values of lung function in the group of younger males were up to $10 \%$ higher compared to the ECCS reference values. In males older than 65 years results were similar to ECCS predicted values or up to $5 \%$ smaller. The data confirm the steeper gradual reduction of lung function parameters with age compared to ECCS formulas.
BOCHUM REFERENCE Formulas FOR Lung FunCTION PARAMETERS OF MALES

VCIN as a static lung volume, the forced expiratory volumes FVC and $\mathrm{FEV}_{1}$, as well as the maximal expiratory flows $\mathrm{PEF}$ and $\mathrm{MEF}_{75,50,25}$ of the healthy males regress linearly to both, age and height $(\mathrm{P}<0.01)$. Extending the range of the ECCS-reference functions until 90 years of age (Table 2), the current values, calculated in $\%$ of the predicted values of ECCS also correlate to age but not to height (as above), indicating 
a steeper slope of the dependency of the listed lung function parameters on age in the subjects investigated. The residual standard deviation (RSD) of the subjects investigated were slightly, but not significantly smaller compared to the ECCS values of RSD, resulting in slightly higher values for the 5 th percentiles.

Bochum function for healthy males demonstrates the steeper slope of the age reduction of $35 \mathrm{ml} /$ year of the compared to $29 \mathrm{ml} /$ year in the ECCS formula. At the age of 25 years $\mathrm{FEV}_{1}$ of a male of $180 \mathrm{~cm}$ height, the Bochum values are $300 \mathrm{ml}$ higher compared to ECCS values. Near the age of 70 years the regression lines cross each other. Since the 5th percentiles have nearly identical $(0.81$ and 0.841 , respectively) the lower limit values only differ in the younger ages.

In a 25 year old male of $180 \mathrm{~cm}$ height, the $5^{\text {th }}$ percentile is $17.8 \%$ smaller compared to the predicted value. At 85 years the difference is $30 \%$ of the predicted value, or nearly twice as much as for a young adult. The coefficients of variation of the measured values in $\%$ predicted of the different lung function parameters were minimally smaller in the groups of young and middle aged males compared to the older group. For $\mathrm{FEV}_{1}$ e.g. the coefficient was 11.9 in the older group, 11.7 in the middle aged and 10.6 in the younger group.

\section{DisCUSSION}

The commonly distributed and largely accepted reference formulas of the ECCS [1,2] for ventilatory lung function are limited in fulfilling the current requirements of lung function testing. The formulas were compiled by the ECCS experts from different investigations and subsets of individuals in the seventies. Meanwhile anthropometrical parameters significantly altered, the population is getting older, and technology is largely improved. The stringent definition of the lower limit value by subtracting $1.64 \cdot \mathrm{RSD}$ with constant RSD wrongs older and smaller subjects effectively. The definition of the lower limit value $\left(5^{\text {th }}\right.$ percentile) is not only important for the discrimination of healthy to diseased, but is also the basis for expert opinions and the amount of compensation for occupational lung diseases.

\section{Extrapolation of ReFERENCE VALues}

Measured lung function values of healthy elderly subjects up to 90 years of age can for our purposes be described by linear regression functions on age and body height. Compared to the ECCS reference formulas, the slopes of the functions were steeper since values for younger subjects were higher than predicted and those of the elderly were slightly lower. The results derived from the older group did not deviate too much from extrapolated ECCS values. So, according to the present results on normal lung function an extrapolation of the reference equations beyond common range of age, applying the same limitations as described for subjects in the middle age range, is justified. Our results do not contradict an extrapolation of ECCS-values beyond the range of the reference values and can act as a makeshift for classification of impaired lung function in older subjects. The alternatively discussed reference equations of the SALPADIA-Study, of NHANES and partially of the LuftiBus-Study are higher, but don't cover all the necessary parameters and/or the age range needed for a comprehensive classification of lung function. A multi centre study for contemporary reference values should be performed in order to solve the problems concerning valid reference values.

\section{Multicenter Study FOR New EuropeAn Lung FUNCTION FORMULAS}

The demand for a complete set of reference values, replacing the ECCS recommendations due the altered structures of our population can be realized only with a great financial, material and personal engagement in a multi centre European research project. At least a number of 20.000 subjects have to be recruited from local registration offices, smokers and diseased subjects excluded and only subjects being qualified are allowed to be selected. Selection in higher age groups will be difficult, as we were faced in our study. In a comprehensive reference value project not only static and dynamic lung volumes and maximal flows should be studied, but also parameters of body plethysmography, diffusion capacities for $\mathrm{CO}$ and blood gases should be studied with identical devices.

The study should be designed to follow longitudinal changes in lung function of adults. A 25 years old male of $190 \mathrm{~cm}$ height will be several $\mathrm{cm}$ smaller at 80 years. Cross sectional studies like ECCS do not integrate age into their formulas for TLC. We don't know if TLC regresses with aging. These open questions can only be answered with a longitudinal study. Recently, the European Respiratory Society established a task force for generation of new reference values of lung function with the aim of compiling current data from early childhood to senescence. A set of recommendations for all ages would be highly convenient, solving the problems of overlaps from adolescence to adults. But for statistical reasons this procedure is highly problematic. In childhood the independent variables for lung function parameters are mainly height and weight, but for young adults these are height, age and sex. So there is a discontinuity in the underlying mathematical model. Stanovic et al. [23, 24] have published something like reference values spanning from childhood to senescence.

\section{ECCS Reference VALues Compared to LuftiBus or SALPAPLDIA-RECOMMENDATIONS}

ECCS predicted values for $\mathrm{FEV}_{1}$ in comparison to the LuftiBus-Study differ by about $200 \mathrm{ml}$ in the middle aged males. For younger and older subjects differences are even smaller. The reference values of the SAPALDIA-Study are about $200 \mathrm{ml}$ higher for young and middle aged males and about $300 \mathrm{ml}$ for more than 65 years old subjects. Lower limit values are largely similar for young subjects by ECCS and LuftiBus, values for middle aged subjects are about $200 \mathrm{ml}$ higher in the LuftiBus study. Despite the decrease of more than 
1.51 from 25 to 80 years of age, the difference between the predicted value and the $5^{\text {th }}$ percentile is nearly constant over the whole range of age. In the original version of the SAPALDIA-Study the lower limit value approximate the predicted values with increasing age [4]. Due to a simplified mathematical model, with respect to the small number of older subjects, the authors newly computed the lower limit values [25]. Now the reference values and lower limit values are almost parallel in the SAPALDIA-Study as we know from ECCS formulas. In the Bochum study, based on data of only 257 healthy subjects, coefficients of variation of the values in \% predicted did not remarkable differ in the younger and older group as one might expect with respect to the differences in $\mathrm{FEV}_{1}$ of about $2.0 \mathrm{~L}$ between a 25 years and an 85 years old male of $180 \mathrm{~cm}$ body height.

\section{INDIVIDUAL REFERENCE VALUES}

For a 50 years old male with $175 \mathrm{~cm}$ body height, the difference in between the $5^{\text {th }}$ and $95^{\text {th }}$ percentiles of $\mathrm{FEV}_{1}$ is nearly $\pm 25 \%$ of the predicted value. A healthy young adult with a $\mathrm{FEV}_{1}$ of $125 \%$, ( $95^{\text {th }}$ percentile) developing a COPD after occupational exposure, requires a deterioration of his functional lung volume of about $50 \%$, more than his left lung volume, before reaching the lower limit value.

In order to improve the sensitivity of the reference values, a registration of individually well measured lung function parameters as individual reference values of young adults before exposition to hazards should be performed. These values can be taken as individual reference and changes apart from the normal annual decline can be detected much earlier. Treatment and occupational hygiene will be more effective. The idea of individual reference values is supported by the German Atemwegsliga offering a 'lung passport' with a table for measurements and a diagram representing lung volumes by age. Recording data into the diagram, steeper changes in $\mathrm{FEV}_{1}$ compared to the normal decline can be detected before a fall below the $5^{\text {th }}$ percentile.

\section{SUMMARY AND CONCLUSION}

Regress of static and dynamic lung function parameter of healthy non smoking males investigated in the Bochum study exceeds the limits of ECCS reference values. In the investigated range of 20-90 years and $160-200 \mathrm{~cm}$ height, linear regres-sions were computed. Static and dynamic parameters of younger adults were signifi-cantly higher and values of elderly adults were slightly lower compared to ECCS values. Using ECCS references as an interim solution, a linear extrapolation beyond the age limit is acceptable. Considering the increasing age and height of our population and the changes in working conditions, a comprehensive multi centre study on lung function of Caucasians should be initiated by the European Community.

Conflicts of interest: No conflicts of interest were reported in relation to this article.

\section{REFERENCES}

[1] Quanjer PH. Standardized lung function testing. Report Working Party Standardization of Lung Function Tests. European Community for Coal and Steel. Bull Eur Physiopathol Respir 1983; 19 Suppl 5: 1-95.

[2] Quanjer P, Tammeling GJ, Cotes JE, Pederson OF, Peslin $\mathrm{R}$, Yernault JC. Lung volumes and forced ventilatory flows. Report of the working party standardization of lung functions tests. European Community for Steel and Coal. Eur Respir J 1993; 69 Suppl 16.

[3] Hankinson JL, Odencrantz JR, Fedan KB. Spirometric reference values from a sample of the general U.S. population. Am J Respir Crit Care Med 1999; 159: 179-187.

[4] Brändli O, Schindler N, Künzli R, Keller A, Perruchoud AP, SAPALDIA Team. Lung function in healthy never smoking adults: reference values and lower limits of normal of a Swiss population. Thorax 1996; 51: 277-282.

[5] Roca J, Sanchis J, Agusti-Vidal A, et al. Spirometric reference values for a Mediterranean population. Bull Eur Physiopathol Respir 1986; 22: 217-224.

[6] Kuster SP, Kuster D, Schindler C, Rochat MK, Braun J, Held L, Brändli $\mathrm{O}$. Reference equations for lung function screening of healthy never-smoking adults aged 18-80 years. Eur Respir J 2008; 31: 860-868.

[7] American Thoracic Society. Lung function testing: selection of reference values and interpretative strategies. Official statement of the American Thoracic Society. Am Rev Respir Dis 1991; 144: 1202-1218.

[8] American Thoracic Society. Standardization of spirometry: 1994 Update. Official Statement of the American Thoracic Society. Am Rev Respir Dis 1995; 152: 11071136.

[9] Crapo RO, Morris AH, Gardner RM. Reference spirometric values using techniques and equipment that meet ATS recommendations. Am Rev Respir Dis 1981; 123: 659664.

[10] Knudson RJ, Slatin RC, Lebowitz MD, Burrows B. The maximal expiratory flow-volume curve: normal standards, variability, effects of age. Am Rev Respir Dis 1976; 113: 587-599.

[11] Knudson RJ, Lebowitz MD, Holdberg CJ, Burrows B. Changes in maximal expiratory flow-volume curve with growth and aging. Am Rev Respir Dis 1983; 127: 725734.

[12] Enright PL, Kronmal RA, Higgins M, et al. Spirometry reference values for women and men 65 to 85 years of age. Am Rev Respir Dis 1993; 147: 125-133.

[13] Enright PL, Beck KC, Sherrill DL. Repeatability of spirometry in 18,000 adult patients. Am J Respir Crit Care Med. 2004; 169: 235-238.

[14] Fletcher C, Peto R. The natural history of chronic airflow obstruction. BMJ 1977; 1: 1645-1648.

[15] Wise RA. The value of forced expiratory volume in 1 second decline in the assessment of chronic obstructive pulmonary disease progression. Am J Med 2006; 119 Suppl 10: 4-11.

[16] Molfino NA. Genetic predisposition to accelerated decline of lung function in COPD. Int J Chron Obstruct Pulmon Dis 2007; 2: 117-119.

[17] Hnizdo E, Sircar K, Yan T, Harber T, Fleming J, Glindmeyer HW. Limits of longitudinal decline for the interpretation of annual changes in $\mathrm{FEV}_{1}$ in individuals. Occup Environ Med 2007; 64: 701-707.

[18] Miller MR, Hankinson JL, Brusasco V, Burgos F, Casaburi R. Standardisation of Spirometry. Eur Respir J 2005; 26: 319-338.

[19] Miller MR, Crapo RO, Hankinson JL, et al. ATS/ERS Task Force: Standardisation of lung function testing: General Considerations of Lung Function Testing. Eur Respir J 2005; 26: 153-161. 
[20] Pellegrino R, Viegi G, Brusasco V, Crapo RO, Burgos F, et al. Interpretative Strategies for Lung Function Testing. Eur Respir J 2005; 26: 948-968.

[21] Marek W, Marek E, Mückenhoff K, Smith HJ, KotschyLang N, Kohlhäufl M. Lungenfunktion im Alter: Brauchen wir neue Referenzwerte? Pneumologie 2009; 63: $235-243$

[22] Sachs L. Angewandte Statistik, Planung und Auswertung, Methoden und Modelle. Berlin, Heidelberg, New York: Springer Verlag, 1992.

[23] Stanojevic S, Wade A, Stocks J, Hankinson JL, Coates AL, Pan H, Rosenthal M, Corey M, Lebecque P, Cole TJ Reference Ranges for Spirometry across all ages. a new approach. Am J Respir Crit Care Med 2008; 177: 253-260.

[24] Stanojevic S, Wade A, Hankinson JL, Coates AL, Stocks J, Cole TJ. Continuous reference ranges for spirometry from childhood to adulthood. Am J Respir Crit Care Med 2007; 176: A606.
[25] Brändli O, Leuenberger P, Schindler N, Baur X, Degens P, Künzli R, Keller R, Perruchoud AP. Reestimated reference equations for the 5 th percentiles of lung function variables in the adults population of Switzerland. (SAPALDIA-Study). Thorax 2000; 55: 173-174.

Author's address:

Wolfgang Marek, PD Dr. rer. nat.

Institute for Occupational Physiology,

Augusta-Kranken-Anstalt

Bergstr. 23

44791 Bochum

Germany

Phone: +492345172474

E-mail: Wolfgang.Marek@ruhr-uni-bochum.de 